\title{
Frequency and risk factors of recurrent pain during refeeding in patients with acute pancreatitis: a multivariate multicentre prospective study of 116 patients
}

\author{
P Lévy, D Heresbach, E A Pariente, A Boruchowicz, R Delcenserie, B Millat , J Moreau, \\ L Le Bodic, L de Calan, M Barthet, A Sauvanet, P Bernades
}

\begin{abstract}
Background/Aims-The period of refeeding in patients with acute pancreatitis is critical because they may have pain relapse. A multicentre, multidimensional, prospective study was performed to assess the frequency and the risk factors of pain relapse in these patients.

Methods-Patients were included if they had acute pancreatitis severe enough to stop oral feeding for more than $\mathbf{4 8}$ hours. Clinical, biochemical, radiological, and therapeutic data were prospectively recorded and analysed by unidimensional and multidimensional analysis. The moment to refeed patients was chosen by the clinician but the diet was the same in all centres.
\end{abstract}

Results-A total of 116 patients were included with a Ranson's bioclinical score $\geq 3$ in $35 \%$ and a Balthazar's CT score $\geq D$ in $42 \%$. The cause of acute pancreatitis was biliary in $47 \%$ and alcohol misuse in $31 \%$. During the oral refeeding period, $21 \%$ of the patients had pain relapse. This occurred on days 1 and 2 in $50 \%$ of patients. The duration of the painful period was longer in patients who relapsed than in others $(p<0.002)$. Pain relapse occurred in $39 \%$ of patients with a serum lipase concentration $>3 \times$ the upper limit of the normal range the day before refeeding and in $16 \%$ of other patients $(\mathbf{p}<0.03)$. Patients with higher Balthazar's CT scores had pain relapse more often than the others $(p<0 \cdot 002)$. None of the therapeutic procedures significantly modified the frequency of pain relapse. Using multidimensional analysis, Balathazar's CT score, period of pain, and serum lipase concentration the day before refeeding were independently associated with an increased risk of pain relapse. At a threshold of 0.5 , a logistic score had a $37 \%$ sensitivity, $95 \%$ specificity, and $83 \%$ accuracy to predict pain relapse. Pain relapse nearly doubled total hospital stay and hospital stay after the first attempt at oral refeeding.

Conclusion-Pain relapse occurred in one fifth of the patients with acute pancreatitis during oral refeeding and was more common in patients with necrotic pancreatitis and with longer periods of pain.
The results of this study can be used to predict high risk patients and are a first step in the prevention of pain relapse. (Gut 1997; 40: 262-266)

Keywords: acute pancreatitis, feeding.

In patients with acute pancreatitis, it is generally agreed that oral feeding must be stopped primarily to alleviate pain but also, perhaps to limit the severity of acute pancreatitis. The refeeding period is critical because pancreatic secretion is again stimulated and patients may have pain or relapse to acute pancreatitis, requiring oral feeding to be stopped once more. No data are available about when to refeed patients or what sort of diet to use. Patients are usually refed small amounts and then the numbers of calories are gradually increased over a three to six day period. ${ }^{1}$

Nevertheless, the frequency and risk factors of pain relapse have never been assessed. We performed a multicentre, multidimensional, prospective study in 11 medical or surgical centres in France, to clearly assess the frequency and risk factors of pain relapse during refeeding in patients with acute pancreatitis. Because of the lack of data, the time at which to refeed patients was chosen by the clinician but the diet was the same in all centres.

\section{Patients and methods}

INCLUSION CRITERIA

All patients with acute pancreatitis admitted to hospital from January 1994 to September 1994 in 11 surgical or medical units were included. Acute pancreatitis was defined as an acute epigastric pain requiring emergency admission to hospital associated with (a) raised serum amylase or lipase $>$ five times the upper limit of normal $(\mathrm{N})$ or (b) ultrasonographic or CT evidence of acute pancreatitis. Patients were included if acute pancreatitis was severe enough to require oral feeding to be stopped for more than 48 hours.

\section{EXCLUSION CRITERIA}

Patients were excluded if they had very severe acute pancreatitis defined as (a) a delay between the onset of symptoms and refeeding 
TABLE I Caloric and fat content during the first five days of refeeding

\begin{tabular}{lll}
\hline Day & Calorie content (kcal) & Lipids (g) \\
\hline 1 & 250 & $<5$ \\
2 & 1000 & $5-10$ \\
3 & 1500 & $15-20$ \\
4 & 1600 & $25-30$ \\
5 & 1700 & $35-40$ \\
\hline
\end{tabular}

of over 30 days or $(b)$ surgery due to a complication of acute pancreatitis (necrosectomy, pancreatic resection).

DATA COLLECTION

The following data were recorded for each patient.

\section{Clinical data}

We recorded sex, age, cause of acute pancreatitis, delay between the onset of symptoms and admission to hospital on the one hand and the discontinuation of oral feeding on the other, cause of acute pancreatitis, the presence of vomiting, the duration of the period of pain, and hospital stay.

\section{Biochemical data}

Maximal serum amylase and lipase concentrations, Ranson's score, ${ }^{2}$ maximal serum C reactive protein concentration (measured every 10 days during the fasting period), serum amylase, and lipase concentrations the day before refeeding were recorded.

\section{Radiological data}

Pancreatic califications, maximal Balthazar's CT score according to the classifications of $1985^{3}$ and $1990,{ }^{4}$ enlarged Wirsung duct on CT (diameter $>4 \mathrm{~mm}$ ), and abdominal collection were recorded.

\section{Therapeutic data}

The use of nasogastric suction, radiological or endoscopic procedures, parenteral nutrition, antibiotics, gastric antisecretory drugs, somatostatin analogues, the delay between the onset of symptoms, the end of the period of pain, and the time of refeeding were noted.
REFEEDING

The decision of when to refeed patients was taken by the clinician responsible. No advice concerning the best time and the concentration of serum pancreatic enzymes was given. Table I lists the refeeding diet, which was the same in all centres. Patients were refed progressively starting with low caloric and low fat intake diets. During the refeeding period, patients were asked daily about abdominal pain. Pain relapse was defined as acute pain requiring oral feeding to be stopped again. Abdominal discomfort was not considered to be pain relapse if refeeding was continued. Serum amylase and lipase concentrations were measured on days 1,2 , and 4 after refeeding.

\section{STATISTICAL METHODS}

Data are given as mean (SEM) or percentage. Univariate analysis was performed by $\chi^{2}$ test or Fisher's exact test for qualitative data, Student's $t$ test or Wilcoxon test for quantitative data. p Values $<0.05$ were arbitrarily considered significant for bilateral tests.

A multidimensional analysis was performed using backward elimination logistic regression analysis. Significant levels to stay in the logistic regression were $0 \cdot 20$. All significant variables determined by univariate analysis were included in the model. A logistic score was calculated. In this model, each individual patient is given a logistic score $=\beta_{1} X_{1}+\beta_{2} X_{2}+\ldots+\beta_{\kappa} X_{\kappa}+C$ in which $\mathrm{X}_{1} \ldots \mathrm{X}_{\kappa}$ are the levels of $\kappa$ prognostic variables, $\beta_{1} \ldots \beta_{k}$ are regression coefficients, and $C$ is a calculated constant factor. The probability $(p)$ of pain relapse is calculated according to the formula: $\mathrm{p}=\exp ^{\text {logistic score }} /\left(1+\exp ^{\text {logistic score }}\right) .^{5-7}$

\section{Results}

PAIN RELAPSE

One hundred and sixteen patients were included in the study in nine months. Table II gives their clinical characteristics. During the oral refeeding period, 24 patients $(21 \%)$ had pain relapse, including five patients with relapse to acute pancreatitis. Pain relapse occurred on days 1 and 2 in $12(50 \%)$ patients and after the second day in $12(50 \%)$ patients. There was no significant difference between the centres for the frequency of pain relapse.

TABLE II Clinical data in the studied population and comparison of patients with or without pain relapse

\begin{tabular}{|c|c|c|c|c|}
\hline & $\begin{array}{l}\text { Total } \\
n=116\end{array}$ & $\begin{array}{l}\text { Patients with } \\
\text { pain relapse } \\
(n=24)\end{array}$ & $\begin{array}{l}\text { Patients without } \\
\text { pain relapse } \\
(n=92)\end{array}$ & $p$ Value \\
\hline $\operatorname{Men}(n(\%))$ & $74(64)$ & $15(63)$ & $59(64)$ & NS \\
\hline $\begin{array}{l}\text { Age (SEM) (M) (y) } \\
\text { Cause of acute pancreatitis }(n(\%))\end{array}$ & $51(4)$ & $51(4)$ & $51(2)$ & NS \\
\hline \multicolumn{5}{|l|}{ Cause of acute pancreatitis $(\mathrm{n}(\%))$} \\
\hline Alcohol & $\begin{array}{l}34(41)) \\
36(31)\end{array}$ & $\begin{array}{l}8(33) \\
8(33)\end{array}$ & $\begin{array}{l}46(30) \\
28(30)\end{array}$ & NS \\
\hline Post-ERCP & $3(3)$ & $3(13)$ & $0(0)$ & 0.008 \\
\hline Miscellaneous & $10(9)$ & $1(4)$ & $9(10)$ & NS \\
\hline Unknown & $13(11)$ & $4(17)$ & $9(10)$ & NS \\
\hline \multirow{2}{*}{\multicolumn{5}{|c|}{$\begin{array}{l}\text { Delay between onset of symptoms and } \\
\text { admission to hospital (days) (M (SEM)) }\end{array}$}} \\
\hline & $1(0 \cdot 6)$ & $1(0 \cdot 6)$ & $1(0 \cdot 2)$ & NS \\
\hline $\begin{array}{l}\text { Delay between onset of symptoms and } \\
\text { stopping oral feeding (days) (M (SEM)) }\end{array}$ & & & & \\
\hline $\begin{array}{l}\text { stopping oral feeding (days) (M (SEM)) } \\
\text { Vomiting ( }(\%))\end{array}$ & $1(0 \cdot 2)[3]^{\star}$ & $1(0 \cdot 6)[1]^{\star}$ & $1(0 \cdot 2)[2]^{\star}$ & NS \\
\hline $\begin{array}{l}\text { Vomiting (n(\%)) } \\
\text { Period of pain (days) (M (SEM)) }\end{array}$ & $\begin{array}{l}72(62) \\
7.0(0.5)[7]^{\star}\end{array}$ & $\begin{array}{l}16(67) \\
11.0(1 \cdot 7)[3]^{\star}\end{array}$ & $\begin{array}{l}56(61) \\
6 \cdot 0(0 \cdot 5)[4]^{\star}\end{array}$ & $<0.002$ \\
\hline
\end{tabular}

*Data not available for number of patients in brackets. 
TABLE II Biochemical data in the studied population and comparison of patients with or without pain relapse

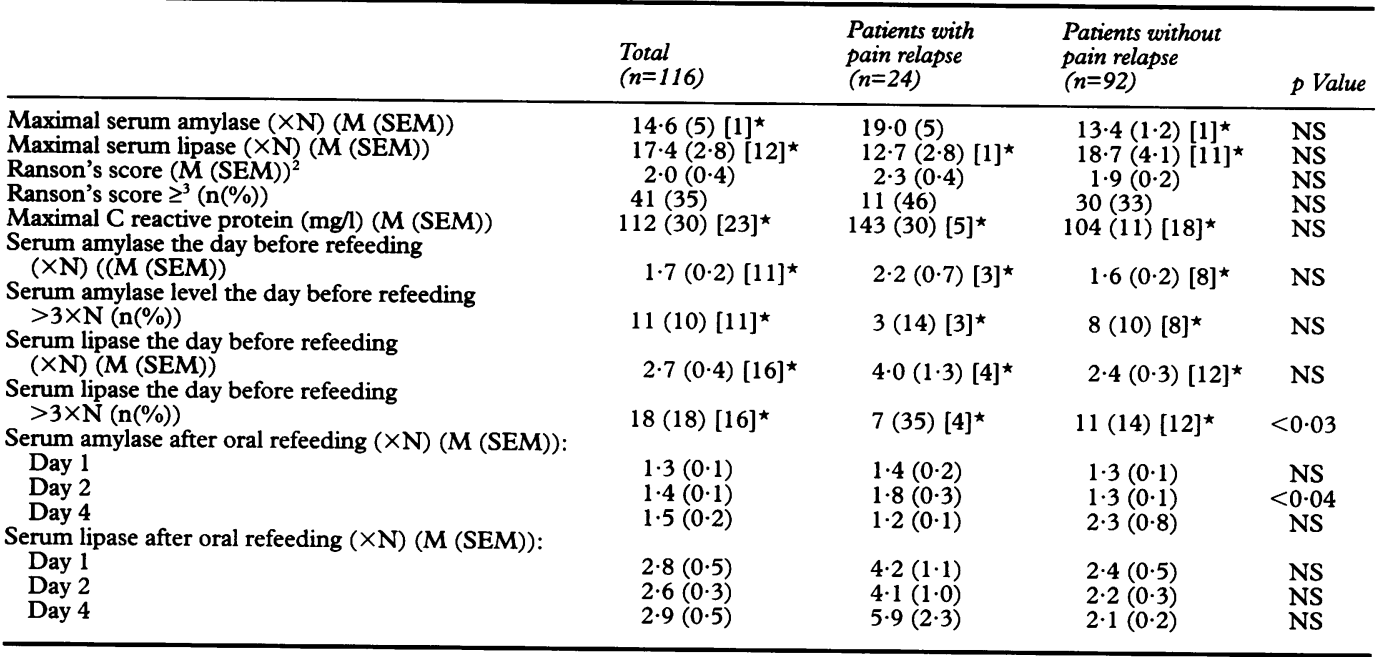

$(\times N)=$ Times the upper limit of the normal range. ${ }^{\star}$ Data not available for numbers of patients in brackets.

TABLE IV Radiological data in the studied population and comparison of patients with or without pain relapse

\begin{tabular}{lcccc}
\hline & $\begin{array}{l}\text { Total } \\
(n=116)\end{array}$ & $\begin{array}{l}\text { Patients with } \\
\text { pain relapse } \\
(n=24)\end{array}$ & $\begin{array}{l}\text { Patients without } \\
\text { pain relapse } \\
(n=92)\end{array}$ & $p$ Value \\
\hline Pancreatic calcifications $(\mathrm{n}(\%))$ & $5(4)$ & $3(12)$ & $2(2)$ & \\
1985 Balthazar's CT score ${ }^{3} \geq \mathrm{D}(\mathrm{n}(\%))$ & $46(42)[5]^{\star}$ & $16(67)[0]^{\star}$ & $30(34)[5]^{\star}$ & $<0 \cdot 002$ \\
1990 Balthazar's CT score $(\mathrm{M}(\mathrm{SEM}))$ & $2 \cdot 6(0 \cdot 5)[5]^{\star}$ & $3 \cdot 9(0 \cdot 5)$ & $2 \cdot 2(0 \cdot 2)[5]^{\star}$ & $<0 \cdot 002$ \\
Enlarged Wirsung duct $(\mathrm{n}(\%))$ & $6(5)$ & $2(8)$ & $4(4)$ & $\mathrm{NS}$ \\
Abdominal collection $(\mathrm{n}(\%)$ & $33(28)$ & $9(37)$ & $24(26)$ & $\mathrm{NS}$ \\
\hline
\end{tabular}

^Data not available for numbers of patients in brackets.

\section{UNIDIMENSIONAL ANALYSIS}

\section{Clinical data}

Table II shows comparisons of clinical data. In three patients, acute pancreatitis was caused by endoscopic retrograde cholangiopancreatography. All these patients had pain relapse when they were refed. The duration of the period of pain was longer in patients who relapsed than in others. There was no other significant difference between the two groups for clinical data (Table II).

\section{Biochemical data}

The only difference between the two groups (Table III) was the serum lipase concentration the day before refeeding when lipase concentrations were separated into two classes $(>3 \mathrm{~N}$ or not). Pain relapse occurred in seven of 18 $(39 \%)$ patients with serum lipase concentrations $>3 \mathrm{~N}$ the day before refeeding and in 13 of $82(16 \%)$ patients with serum lipase concentrations $\leq 3 \mathrm{~N}$ (data not available in 16 patients). Maximal serum amylase, lipase, and $C$ reactive protein concentrations and Ranson's score were not associated with an increased risk of pain relapse. Serum amylase and lipase concentrations did not increase during refeeding. Serum amylase concentrations were significantly higher the second day after refeeding in patients with pain relapse.

RADIOLOGICAL DATA

Patients with higher 1985 and 1990 Balthazar's CT scores had pain relapse more often than others (Table IV). Pain relapse occurred in 16 of 46 (35\%) patients with 1985 Balthazar's CT score $\geq D$ and in eight of $65(12 \%)$ patients with 1985 Balthazar's CT score $<\mathrm{D}^{3}$ (data not available in five patients). There was no difference between the two groups if pancreactic calcifications, enlarged Wirsung duct, or abdominal collection were present or not.

\section{Therapeutic data}

None of the therapeutic procedures performed to treat acute pancreatitis significantly modified the frequency of pain relapse (Table V). The delay between the onset of symptoms, the end of the period of pain, and refeeding were not associated with an increased risk of pain relapse.

\section{MULTIDIMENSIONAL ANALYSIS}

All the significant parameters determined by unidimensional analysis were tested in the model. Using multidimensional analysis, 1985 Balathazar's CT score, period of pain, and serum lipase concentration the day before refeeding were independently associated with an increased risk of pain relapse. The logistic score to predict the risk of pain relapse calculated according to this model was $0.64 \mathrm{a}+1 \cdot 11$ $b+2.18 c-9.06$ in which a is 1985 Balathazar's CT score (five classes), $b$ is the duration of the painful period (five classes), $c$ is serum lipase concentration on the day before refeeding $>3$ $\mathrm{N}$ (two classes), and $\mathbf{9 . 0 6}$ is a constant factor. The Figure gives the probability of pain relapse in relation to the logistic score. At a threshold 
TABLE V Therapeutic data in the studied population and comparison of patients with or without pain relapse

\begin{tabular}{|c|c|c|c|c|}
\hline & $\begin{array}{l}\text { Total } \\
(n=116)\end{array}$ & $\begin{array}{l}\text { Patients with } \\
\text { pain relapse } \\
(n=24)\end{array}$ & $\begin{array}{l}\text { Patients without } \\
\text { pain relapse } \\
(n=92)\end{array}$ & p Value \\
\hline $\begin{array}{l}\text { Nasogastric suction }(\mathbf{n}(\%)) \\
\text { Radiological procedures }(\mathrm{n}(\%)) \\
\text { Endoscopic procedures }(\mathrm{n}(\%)) \\
\text { Parenteral nutrition }(\mathrm{n}(\%)) \\
\text { Use of antibiotics }(\mathrm{n}(\%)) \\
\text { Use of gastric antisecretory drugs }(\mathrm{n}(\%)) \\
\text { Use of somatostatin analogs }(\mathrm{n}(\%)) \\
\text { Delay between onset of symptoms and oral refeeding }\end{array}$ & $\begin{array}{l}60(52) \\
2(2) \\
31(27) \\
61(53) \\
48(41) \\
55(47) \\
12(10)\end{array}$ & $\begin{array}{r}13(54) \\
0(0) \\
5(21) \\
131(54) \\
10(42) \\
11(46) \\
5(21)\end{array}$ & $\begin{array}{c}47(51) \\
2(2) \\
26(28) \\
48(52) \\
38(41) \\
44(48) \\
7(8)\end{array}$ & $\begin{array}{l}\text { NS } \\
\text { NS } \\
\text { NS } \\
\text { NS } \\
\text { NS } \\
\text { NS } \\
\text { NS }\end{array}$ \\
\hline $\begin{array}{l}\text { (days) (M (SEM)) } \\
\text { Delay between end of period of pain and oral refeeding }\end{array}$ & $12(0 \cdot 8)$ & $15(2 \cdot 1)$ & $11(0 \cdot 8)$ & NS \\
\hline (days) (M (SEM)) & $6(0 \cdot 7)[9]^{\star}$ & $6(1 \cdot 9)[4]^{\star}$ & $6(0 \cdot 7)[5]^{\star}$ & NS \\
\hline
\end{tabular}

^Data not available for number of patients in brackets.

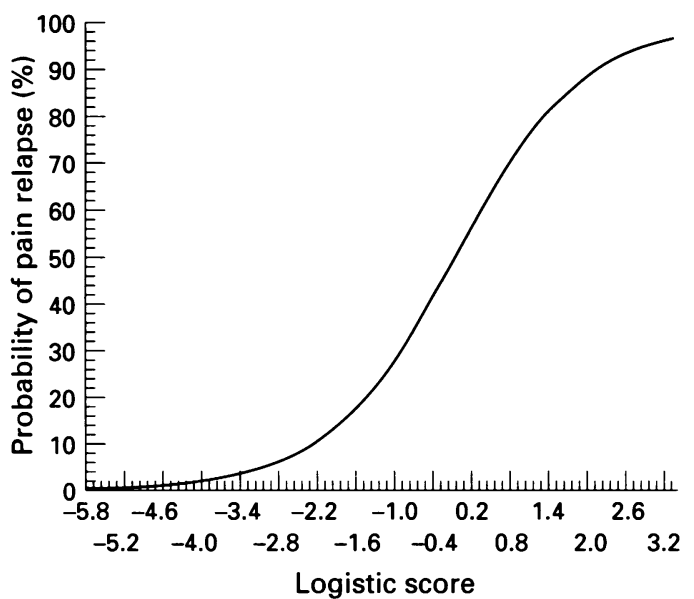

Probability of pain relapse according to the logistic score.

of $0 \cdot 5$, logistic score had $37 \%$ sensitivity, $95 \%$ specificity, and $83 \%$ accuracy to predict pain relapse.

\section{HOSPITAL STAY}

Table VI gives the results. Pain relapse nearly doubled total hospital stay and hospital stay after the first attempt at oral refeeding.

\section{Discussion}

This is the first study assessing the frequency and risk factors of pain relapse during the refeeding period in patients with acute pancreatitis after a fasting period $>48$ hours. Pain relapse occurred in $21 \%$ of patients, mainly in those with a long period of pain, necrotic acute pancreatitis (1985 Balthazar's CT score $\geq D^{3}$ ), and with serum lipase concentrations just before refeeding $>3 \mathrm{~N}$. In these patients, the risk of pain relapse was $35 \%-39 \%$. The logistic score calculated by the logistic regression had a low sensitivity but a high specificity for the prediction of pain relapse. In patients with the most severe forms of acute pancreatitis requiring many weeks in intensive care or pancreatic surgery, oral refeeding is a secondary problem. For this reason, we decided to exclude these patients.

As risk factors, we recorded and tested patient characteristics, radiological data, and the most widely used prognostic factors: Ranson's score, ${ }^{2} \mathrm{C}$ reactive protein, ${ }^{8}$ and Balthazar's CT scores. ${ }^{34}$ As a result, we could record many cases in a few months with few missing data in each case. We did not use the APACHE II score ${ }^{9}$ as it is less extensively used in French centres involved in the treatment of acute pancreatitis and we decided to use the first score published by Ranson $e t a l^{2}$ as a multiparameter scoring system. The same authors have shown that this score was less accurate in patients with biliary acute pancreatitis than a second score defined in another paper. ${ }^{10}$ Nevertheless, we did not use this second score because (a) the diagnosis of gall stones is not always available on admission, $(b)$ some patients with alcoholic acute pancreatitis would have been evaluated using one score and patients with biliary acute pancreatitis with another leading to a less powerful statistical analysis.

There are no published data about when to refeed patients with acute pancreatitis or about the importance of serum pancreatic enzyme concentrations being below the upper limit of the normal range. As a result, we did not establish any time or serum pancreatic enzyme concentration threshold before refeeding patients. Each clinician decided to refeed patients when he thought it was reasonable and safe. Consequently, we considered the time between the onset of symptoms on the one hand, the end of the period of pain on the other hand, and refeeding and the level of serum pancreatic enzyme as parameters. In the present study, the moment that patients were refed did not seem important. Nevertheless, a randomised study assessing the best moment

TABLE VI Hospital stay for patients with or without pain relapse

\begin{tabular}{|c|c|c|c|c|}
\hline & $\begin{array}{l}\text { Total } \\
(n=116)\end{array}$ & $\begin{array}{l}\text { Patients with } \\
\text { pain relapse } \\
(n=24)\end{array}$ & $\begin{array}{l}\text { Patients without } \\
\text { pain relapse } \\
(n=92)\end{array}$ & $p$ Value \\
\hline \multirow{2}{*}{$\begin{array}{l}\text { Total hospital stay (days) (M (SEM)) } \\
\text { Hospital stay after the 1st attempt at oral refeeding } \\
\text { (days) (M (SEM)) }\end{array}$} & $21(1)[6]^{\star}$ & $33(3)[3]^{\star}$ & $18(1)[3]^{\star}$ & $<0.001$ \\
\hline & $9(1)[8]^{\star}$ & $18(3)[3]^{\star}$ & $7(1)[5]^{\star}$ & $<0.001$ \\
\hline
\end{tabular}

^Data not available for number of patients in brackets. 
to refeed patients is warranted. Serum lipase concentrations $>3 \mathrm{~N}$ the day before refeeding was associated with an increased risk of pain relapse. A high serum pancreatic enzyme concentration is a hallmark of persistant pancreatic inflammation which may be associated with an increased risk of relapse.

How to refeed patients with acute pancreatitis is also a problem which has not been answered in the medical literature. ${ }^{1}$ We empirically required all teams to use a similar diet with low caloric and low fat intake in the first days, and to progressively increase calories and fat over five days. Despite this progressive regimen, pain relapse occurred within the first two days of refeeding in half the patients when caloric and fat intakes were still very low.

Pain relapse nearly doubled the hospital stay for patients with acute pancreatitis. Predicting and preventing pain relapse may therefore be cost effective but the means to prevent pain relapse in high risk patients must be tested in further studies. Predicting high risk patients is a first step in this process.
We thank Drs C Hospital-Delanglade and F Dyard, and Laboratoires Solvay-Pharma for their financial support, and Dr F Sevenier (Société Fovéa) for the statistical analysis.

1 Banks PA. Medical management of acute pancreatitis and complications. In Go VLW, DiMagno EP, Gardner JD, Lebenthal E, Reber HA, Scheele GA, eds. The pancreas. Biology, pathobiology, and disease. New York: Raven Press, 1993: 593-611.

2 Ranson JHC, Rifkind KM, Roses DF, Fink SD, Enf K, Spencer FC. Prognostic signs and the role of operative management in acute pancreatitis. Surg Gynecol Obstet 1974;139: 69-81.

3 Balthazar EJ, Ranson JHC, Naidich DP, Megibow AJ, Caccavale R, Cooper MM. Acute pancreatitis: prognostic Caccavale R, Cooper MM. Acute pancreatitis
value of CT. Radiology 1985;136: 767-72.

4 Balthazar EJ, Robinson DL, Megibow AJ, Ranson JHC. Acute pancreatitis: value of CT in establishing prognosis. Radiology 1990; 174: 331-6.

5 Lee ET. A computer program for linear logistic regression analysis. Computer programs in Biomedecine 1978: 80-92.

6 McCullagh P, Nelder JA. Generalized linear models. 2nd ed. New York: Chapman and Hall, 1989.

7 Nelder JA, Wedderburn RWM. Generalized linear models. Journal of the Royal Statistical Society Series A 1989; 135: $761-8$

8 Viedma JA, Pérez-Mateo M, Agullò J, Dominguez JE, Carballo $\mathrm{F}$. Inflammatory response in the early prediction of severity in human acute pancreatitis. Gut 1994; 35: $822-7$.

9 Wilson C, Heath DI, Imrie CW. Prediction of outcome in acute pancreatitis: a comparative study of APACHE II, clinical assessment and multiple factor scoring systems. Br F Surg 1990; 77: 1260-4

10 Ranson JHC. The timing of biliary surgery in acute pancreatitis. Ann Surg 1979; 189: 654-63. 